\title{
Research on a New Mine-Used NPC-Type Three Electrical Level Reactive Power Compensator and its Decoupling Control
}

\author{
$\mathrm{Na} \mathrm{Gu}{ }^{1,}$, , Xiaofeng $\mathrm{Ji}^{2, \mathrm{~b}}$ \\ ${ }^{1}$ Nantong Polytechnic College, China \\ ${ }^{2}$ Nantong Shipping College, China \\ aguna0513@163.com, ㄹmike0072@163.com
}

Keywords: three electrical level, SVPWM, dq axis decoupling, reactive power compensation

\begin{abstract}
The wide application of inductive loads in the mine industry introduces the harmonic current to the electric gird, which pollutes the power grid and further do harm to the electric equipment. To resolve this problem, a novel NPC-type three electrical level reactive power compensator is presented in this paper. The circuit structure and operating principle are first studied, based on which, the dynamic mathematic model is built. With the introduction of current feedforward control strategy and SVPWM, the dynamic decoupling strategy between active and reactive current is proposed. For the decoupled reactive subsystem, the PI regulator is also designed to ensure the closed-loop stability. The MATLAB/Simulink based simulation model of the proposed control system is constructed, and the corresponding simulation and experiments are preformed, whose results demonstrate the correctness and effectiveness of the proposed strategy.
\end{abstract}

\section{Introduction}

With the growing of coal industry, underground mining, transportation and other work develop to the mechanization and automation, various high-power coal mining and transportation machinery increased dramatically. Most of these electric devices are inductive load, producing large amounts of reactive power in the grid system, resulting in a decline in the quality of power supply [1], and even affecting the normal operation of the grid, it is necessary to compensate for reactive power.

Large number of theoretical studies and field practice show that the traditional two-level compensation is difficult to meet the performance requirements of mine reactive power compensation, The reason is as follows: (1) the two-level compensation is difficult to directly achieve high pressure, high-power technology, limited by maximum voltage and maximum current; (2) the increasing of Switching losses, a corresponding increasing of electromagnetic interference, affect the normal operation of electrical equipment, because of great voltage stress exported by traditional two-level compensator[2]. The concepts and design methods of multi-level compensator in the coal mine power grid have therefore been coined, gradually getting the extensive research and application. The basic topologies can be divided into three categories: Diode clamped multi-level compensator, flying capacitor multi-level compensator and cascaded multi-level compensator[3]. For the flying capacitor multi-level compensator, the volume and cost of the system greatly increased due to the extensive use of capacitive element; Simultaneously, the output of the same level of compensation has a different switch combination, making the control system being very complex. Cascaded multi-level compensator has the advantages of less number of components, modular structure, etc. but it is difficult to achieve four-quadrant operation, and the system requires multiple independent DC power, leading the increasing of volume and cost. Diode clamped multi-level compensation effectively overcome the shortcomings of the presence of the two compensators, addressing the problem of lower pressure of power electronic devices, attracting widespread attention in recent years. Currently, three level compensator is most widely applied in the multilevel diode clamping type compensator, especially in the application of high-power electric power system, which has the advantages of switch device under low pressure drop, low electromagnetic interference, efficiency high advantages. 
Aiming at multi-inductive load, large reactive power in the mine grid and other problems, a novel NPC-type three electrical level reactive power compensator is presented in this paper. Based on the analysis of the main circuit structure and working principle, we establish the mathematical model of three level compensator; Using SVPWM, we design the double closed loop control strategy based on $\mathrm{dq}$ axial decoupling, realizing astatic regulation of the active current and reactive current, effectively eliminating the influence of the network-side voltage and the current disturbance caused by load changes. Finally, the simulation results show the correctness and feasibility of the program.

\section{Structure and Working Principle of NPC Three-level Compensator}

The main circuit structure of NPC three-level compensator is as shown in Fig. 1, Three-level compensator is connected to the grid via coupled inductor ,there are three voltage values exported by AC-side each phase bridge arm, namely Udc/2, 0, -Udc/2. In Phase A Case Study, Three-level compensation for each phase leg has four power switching devices (Sa1, Sa2, Sa3 and Sa4), 4 -wheeling diode and two clamping diodes (DA1, DA2). The midpoint of two serial devices is connected to the midpoint of the DC side capacitor by clamping diodes, making the output voltage be clamped at the DC side midpoint potential, namely the withstand voltage of each switch device being limited to the capacitor voltage[4], so as to achieve the purpose of high voltage output with low voltage switch device. When $\mathrm{Sa} 1$ and $\mathrm{Sa} 2$ is turned on, $\mathrm{Sa} 3$ and $\mathrm{Sa} 4$ off, the output voltage of A-phase $\mathrm{AC}$ side is $\mathrm{Udc} / 2$, expressed by $\mathrm{P}$ state; when $\mathrm{Sa} 2$ and $\mathrm{Sa} 3$ is turned on, Sa1 and $\mathrm{Sa} 4$ off, the output voltage of A-phase AC side is zero, with the $\mathrm{O}$ state representation; when $\mathrm{Sa} 3$ and $\mathrm{Sa} 4$ conduction, $\mathrm{Sa} 1$ and $\mathrm{Sa} 2$ off, the output voltage of A-phase $\mathrm{AC}$-side is $-\mathrm{Udc} / 2$, represented by $\mathrm{N}$ states.

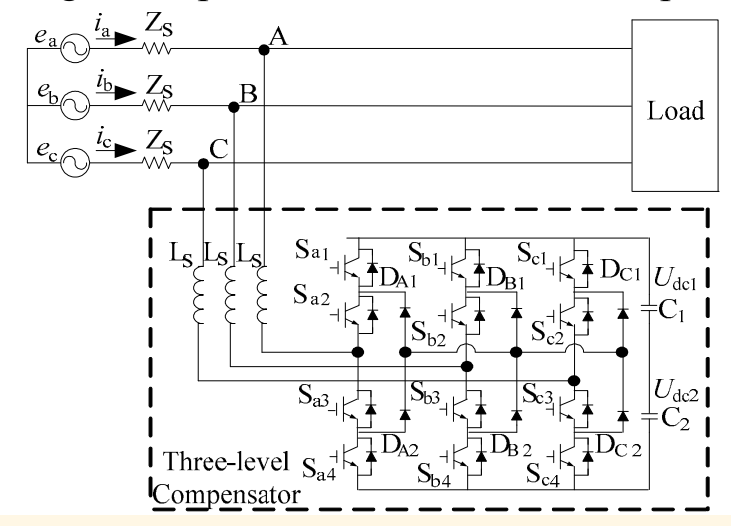

Fig.1 Block diagram of three electrical level compensator

\section{Three-level SVPWM Achieve}

Define the reference voltage vector is:

$$
V_{\text {ref }}=\left|V_{\text {ref }}\right| \mathrm{e}^{\mathrm{j} \theta}
$$

$|V r e f|$ is the modulo value of the reference voltage vector, and $\theta$ is the phase angle of the reference voltage vector.

SVPWM is a modulation method that the average phase voltage vector exported by Compensator to approximate the reference voltage vector Vref. In the three electrical level compensator, The AC side of each phase has three output state. Considering the three electrical level compensator with three-phase bridge arm, the corresponding has $3^{3}=27$ kinds of switch state combination, which can be divided into four categories: zero vector, a small vectors, vector, large vectors. Putting these vectors in a two-dimensional plane, we can get space voltage vector distribution in $\beta$ - $\alpha$ coordinates, shown in Fig. 2 . 


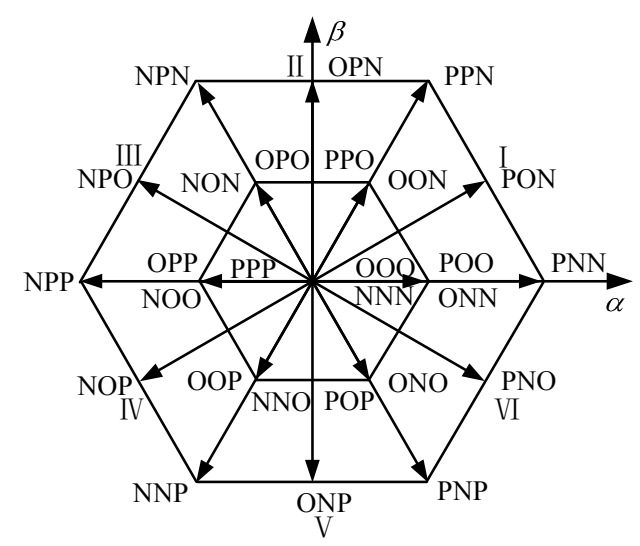

Fig.2 Space vector distribution of three electrical level compensator

\section{SVPWM Modulation Method}

In Fig. 2, starting from $\alpha$ axis, turning counterclockwise every $60^{\circ}$ is defined as a large area, so that the entire space is divided into six large sectors $(\mathrm{I} \sim \mathrm{VI})$. Each sector is further divided into six small range. The division of sector $I$ is as shown in figure 3. At this point, the reference voltage vector Vref falls in the area 2. According to a recent triangular vector method (NTV)[5] with three switching interval vector in which the vertices of a triangle zone synthesizes Vref which is synthesized by vector $V 0, V 1, V 2$. According to the volt-second balance principle[6], you can calculate the duration of action of the three vectors. Finally, by determining the sequence of the basic vectors, SVPWM modulation pulse can be obtained by using the central symmetrical seven-segment pulse sequence.

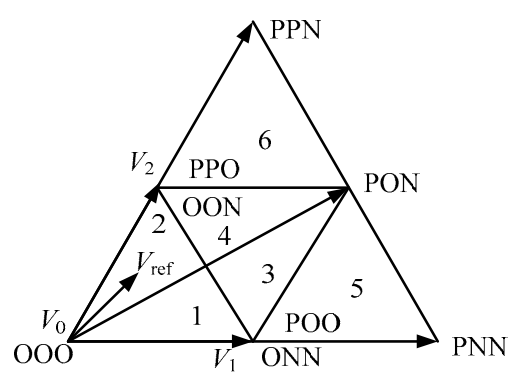

Fig.3 Space voltage vector of sector I

\section{Design of Three-level Compensator Double Closed Loop System}

In order to make the reactive power compensation achieve good results, the closed-loop control system based on dual voltage outer and inner current loop is used in this paper because of the clear physical meaning, simple control structure and excellent control performance, whose structure is shown in Fig. 4. $U_{\mathrm{dc}}^{*}$ as the input given, $U_{d c}$ as DC-side feedback voltage of the compensator, ed, eq as feed forward compensation of system, the current feedback status $\omega L s i d, \omega L s i q$ are introduced for feed forward decoupling to achieve the current independent control. The main role of voltage outer is to control the DC voltage of the compensator; the main action of current inner is to control current based on current command exported by the voltage outer. 


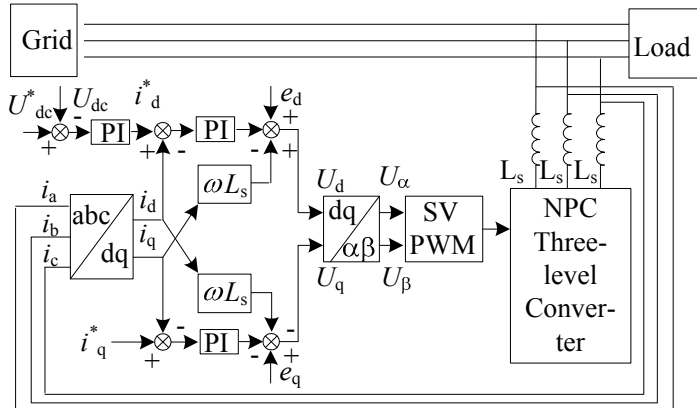

Fig. 4 Block diagram of control system for three-level compensator

\section{Simulation Analysis}

According to the mathematical model and the control strategy established in this paper, based on MATLAB/SIMULINK platform, we build simulation systems and conduct simulation analysis for control strategies and methods designed.

Fig. 5 is the grid voltage and current waveform before and after compensation, the phase difference between the grid voltage and current is existence before compensation, the grid voltage and current phase is basically the same after compensation, and the power factor of the electric network is improved. The DC -side voltage waveform of the compensator is shown in Fig. 6, stabilized at $800 \mathrm{~V}$, voltage deviation within $\pm 5 \mathrm{~V}$ range. The resistive inductive load is added suddenly at the $0.35 \mathrm{~s}$, then the active and reactive current response are shown in Fig. 7. Seeing from Fig. 7, we realize the independent control of active current and reactive current by dq axis decoupling control, the system has good stability and dynamic.

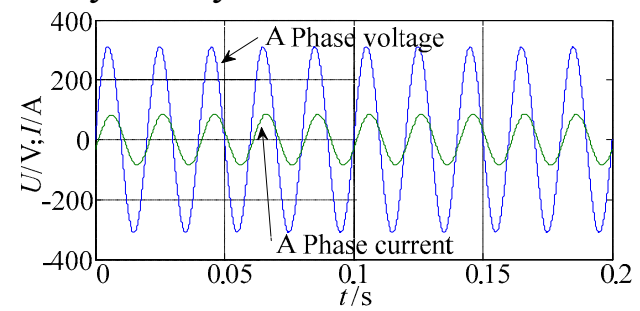

(a) A phase voltage and current waveform before compensation

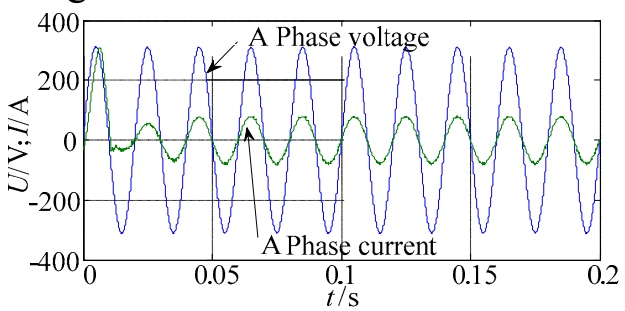

(b) A phase voltage and current waveform after compensation

Fig. 6 System waveforms of voltage and current

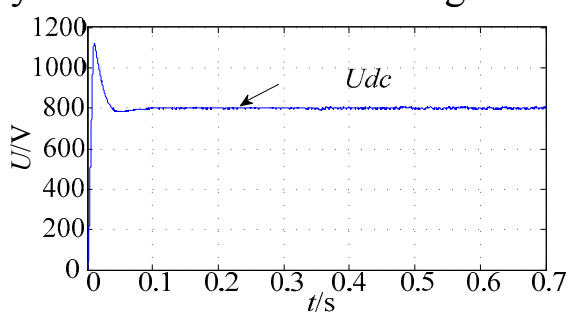

Fig.7 Output voltages of DC link 


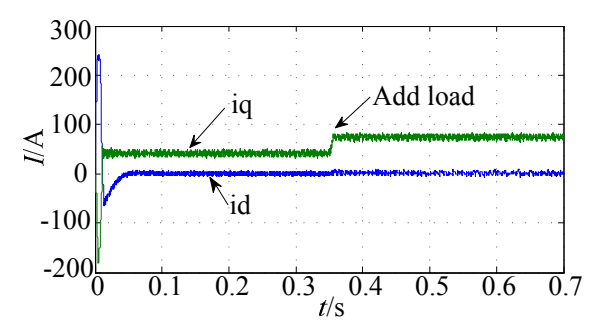

Fig. $7 i_{d}, i_{q}$ component of line current or a sudden load change

\section{Conclusions}

This paper studies a new mine-used NPC-Type three electrical level reactive power compensator, analyzing the structure and working principle of the main circuit, On the basis of the establishment of a three-level NPC compensation mathematical model, we establish the dual-loop control system of the voltage outer and inner current loop using feed forward decoupling strategies based on the dq axis and SVPWM modulation, the method $t$ achieves the independent regulation of active current and reactive current. The simulation verified the effectiveness and excellence of the strategy.

\section{Acknowledgements}

This work is financially supported by Graduate Innovation of Jiangsu Province (CXZZ13_0683).

\section{References}

[1] SHI Li-ping, CHANG Wei, SHI Pei-lei. Research of Mine 6kV High-power Static Synchronous Compensator. Coal Mine Mach-inery, Vol. 11(2011), No. 32, p. 76-79.

[2] LI Ding-zhen, CHEN Bin-yan. Study of Static Synchronous Compensator Based on MATLAB. Electrical Measurement \& Instrumentation, Vol. 48(2011), No.1, p. 49-53.

[3] LIU Miao, HONG Feng, WANG Cheng-hua. Flying-capacitor Dual Buck Five-level Inverter. Proceedings of the CSEE, Vol. 12(2012), No.32, p. 14- 21.

[4] Sergio B., Josep B., Dushan B. The Nearest Three Virtual Space Vector PWM-a Modulation for the Comprehensive Neutral-point Balancing in the Three-level NPC Inverter. IEEE Power Electronics Letters, Vol. 2(2004), No.1, p. 11-15.

[5] Amit Kumar Gupta, Ashwin M.Khambadkone. A Space Vector PWM Scheme for Multilevel Inverters Based on Two-level Space Vector PWM. IEEE Transactions on Industrial Electronics, Vol. 53(2006), No.5, p. 1631-1639.

[6] JIANG Wei-dong, DU Shao-wu, CHANG Liu-chen et al. Hybrid PWM Strategy of SVPWM and VSVPWM for NPC Three-level Voltage-source inverter. IEEE Transactions on Power Electronics, Vol. 25(2010), No.10, p. 2607-2619. 